\title{
Erratum to: Identification of anisotropic vibrational properties of Padauk wood with interlocked grain
}

\author{
Iris Brémaud • Pierre Cabrolier · Joseph Gril • \\ Bruno Clair · Jean Gérard · Kazuya Minato • \\ Bernard Thibaut
}

Published online: 17 September 2010

(C) Springer-Verlag 2010

\section{Erratum to: Wood Sci Technol (2010) 44:355-367 DOI:10.1007/s00226-010-0348-0}

Due to a processing error the caption of Fig. 1 and the third sentence of the conclusion were incorrect. The description of a system of axis [1, 2, 3] was wrongly replaced by (Akitsu et al. 1993; Aramaki et al. 2007; Bodig and Jayne 1982). The corrected caption and the sentence are given below.

Fig. 1 Schematic view of the sampling procedure and of the systems of axis related to the trunk and specimens $[\mathrm{R}, \mathrm{T}, \mathrm{L}]$ and to the grain direction $[1,2,3]$.

Conclusion. (...) Mechanical parameters in the fibre-related system of axis $[1,2,3]$ were identified for untreated and extracted Padauk wood. (...)

The online version of the original article can be found under doi:10.1007/s00226-010-0348-0.

I. Brémaud $(\bowtie) \cdot$ K. Minato

Laboratory of Forest Resource Circulating Circles, Graduate School of Life and Environmental Sciences, Kyoto Prefectural University, Kyoto 606-8522, Japan

e-mail: iris_bremaud@hotmail.com

I. Brémaud · P. Cabrolier · J. Gril · B. Clair

Laboratoire de Mécanique et Génie Civil, CNRS - Université Montpellier 2, Place E. Bataillon, cc 048, 34095 Montpellier cedex 5, France

J. Gérard

Tropical and Mediterranean Forest Products, CIRAD, TA B40/16 BP 5035,

34398 Montpellier cedex 5, France

B. Thibaut

UMR Ecologie des Forêts de Guyane, CNRS, BP 316, 97379 Kourou cedex, French Guyana 